\title{
Modeling, analysis, and screening of cyclic pressure pulsing with nitrogen in hydraulically fractured wells
}

\author{
Emre Artun $^{1} \cdot$ Ali Aghazadeh Khoei ${ }^{1,2} \cdot$ Kutay Köse $^{1}$
}

Received: 16 July 2015/ Published online: 19 July 2016

(c) The Author(s) 2016. This article is published with open access at Springerlink.com

\begin{abstract}
Cyclic pressure pulsing with nitrogen is studied for hydraulically fractured wells in depleted reservoirs. A compositional simulation model is constructed to represent the hydraulic fractures through local-grid refinement. The process is analyzed from both operational and reservoir/ hydraulic-fracture perspectives. Key sensitivity parameters for the operational component are chosen as the injection rate, lengths of injection and soaking periods and the economic rate limit to shut-in the well. For the reservoir/ hydraulic fracturing components, reservoir permeability, hydraulic fracture permeability, effective thickness and half-length are used. These parameters are varied at five levels. A full-factorial experimental design is utilized to run 1250 cases. The study shows that within the ranges studied, the gas-injection process is applied successfully for a 20-year project period with net present values based on the incremental recoveries greater than zero. It is observed that the cycle rate limit, injection and soaking periods must be optimized to maximize the efficiency. The simulation results are used to develop a neural network based proxy model that can be used as a screening tool for the process. The proxy model is validated with blind-cases with a correlation coefficient of 0.96 .
\end{abstract}

Emre Artun

artun@metu.edu

1 Petroleum and Natural Gas Engineering Program, Middle East Technical University, Northern Cyprus Campus, Kalkanli, Guzelyurt, 99738 Mersin 10, Turkey

2 Present Address: University of Tulsa, Tulsa, Oklahoma, USA

Edited by Yan-Hua Sun
Keywords Cyclic pressure pulsing · Nitrogen injection · Hydraulically-fractured wells - Experimental design . Artificial neural networks

\section{Introduction}

In low-permeability reservoirs, which are dissected by a network of interconnected fractures, solution channels, and vugs, water and gas flooding have been found to be ineffective secondary recovery methods (Raza 1971). The injected fluid tends to the channel through the high-conductivity network and bypass the low-permeability, oilbearing matrix. In this type of reservoirs, cyclic pressure pulsing using different types of gases as an alternative method to improve recovery has been found to be effective. Injected gas can penetrate and diffuse through the lowpermeability matrix with the help of the large contact area, which is created by fractures. High-permeability fractures allow easy delivery of the injected gas and production of oil. Well-to-well connectivity is not required as it is a single-well process. The process is characterized by three stages, which are also illustrated in Fig. 1:

(1) Injection period Gas is injected into the reservoir.

(2) Soaking period Gas diffuses from fractures into the matrix.

(3) Production period The well is put on production. At the beginning of production, gas may be produced at high rates; however, as time passes by, it will decrease. Production may continue until the economic limit is reached, and if necessary, another cycle can be initiated.

Since the 1960s a number of studies have been published on cyclic-pressure pulsing. Initial applications were 


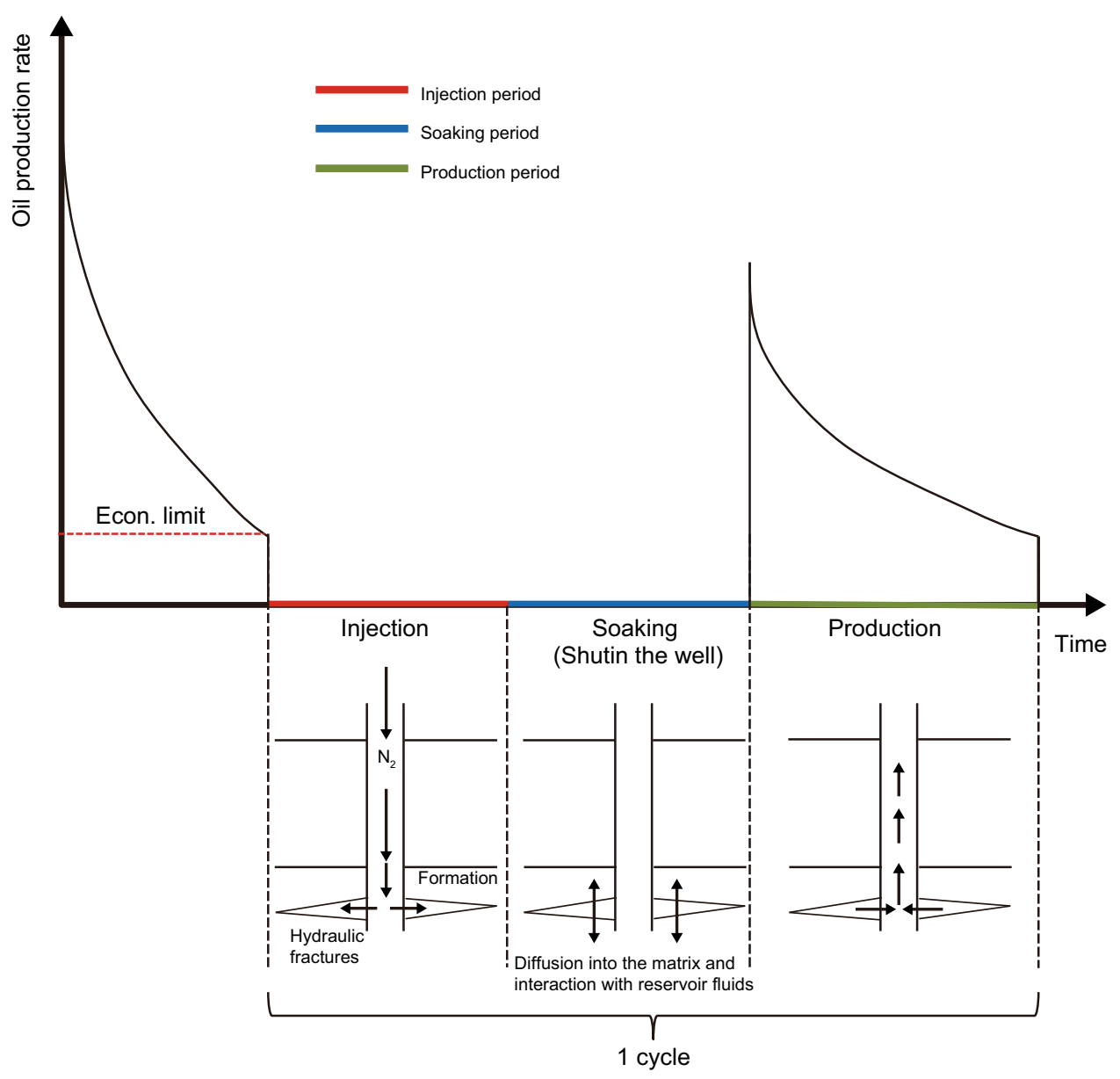

Fig. 1 Overview of the cyclic-pressure-pulsing process and its resulting impact on the produced oil-flow rate

with water as an improved way of waterflooding (Owens and Archer 1966; Felsenthal and Ferrell 1967; Raza 1971). Shelton and Morris (1973) used rich hydrocarbon gases instead of steam to increase the reservoir energy (as a short-term benefit) and reduce oil viscosity (as a long-term benefit). Moreover, they found that soaking mainly affects the peak production rate after injection. Later, cyclic injection of carbon dioxide was utilized for heavy oil in California (Sankur and Emanuel 1983), Arkansas (Khatib et al. 1981), and Turkey (Bardon et al. 1986), and for light and medium types of oil in Kentucky (Bardon et al. 1994), Texas (Haskin and Alston 1989), and Louisiana (Monger and Coma 1988). In the 1990s and 2000s, nitrogen and mixtures with nitrogen were proposed and successfully applied (Shayegi et al. 1996; Miller and Gaudin 2000). Artun et al. (2010, 2011a, b, 2012) performed detailed parametric studies of the process by analyzing a large set of reservoir simulation runs and developed proxy models to be used for screening and optimization of cyclic pressure pulsing with nitrogen and carbon dioxide in naturally fractured reservoirs. These studies showed that cyclic pressure pulsing can be an effective enhanced oil recovery method in naturally fractured reservoirs. Nitrogen has several advantages over carbon dioxide and other types of gases because of being inert, non-corrosive, environmentally friendly and cost effective (Miller and Gaudin 2000). In fractured systems, the primary mechanism that contributes to the displacement of oil is the gas diffusion through the surface of the fracture network. While naturally fractured reservoirs provide an extensive surface area for diffusion, hydraulic fractures can help to achieve a similar mechanism to some extent. In recent studies, it was shown that the cyclic pressure pulsing with water, nitrogen and carbon dioxide (Gamadi et al. 2014; Sheng and Chen 2014; Sheng 2015) can be an effective method to improve recovery in shale oil and liquid-rich shale reservoirs which benefit from an extensive network of hydraulic and natural fractures.

There are many hydraulically fractured wells in the world, and some of these wells are producing depleted reservoirs with very low production rates. Oil fields of the Appalachian Basin in the North-East USA can be given as 
examples with majority of the wells being hydraulically fractured and reservoir pressures at depleted levels. This makes most of the wells in the region classified as stripper wells, producing at marginal oil rates (typically less than 10 barrels per day). Such reservoir conditions require enhanced oil recovery methods to increase the production rate while low profit margins make it difficult to justify conventional flooding-type enhanced oil recovery methods. In this study, we propose that the cyclic pressure pulsing with nitrogen as a promising enhanced oil recovery method that can benefit from the existing hydraulic fractures in the well even though there is not an existing natural-fracture network. In addition, low-cost requirements of nitrogen generated from a membrane unit would help the process to be attractive from a feasibility point of view. The primary objectives of the study are understanding the following: (1) Applicability of cyclic pressure pulsing with nitrogen in hydraulically fractured wells in the Appalachian Basin-like reservoirs and others; and (2) Impact of various reservoir and operational parameters on the process efficiency.

To achieve the objectives, the workflow shown in Fig. 2 is followed which starts with a representative reservoir model. The investigation is accomplished using a compositional numerical reservoir model, which is characterized with representative properties of Appalachian Basin sandstones and Mid-Continent crude oil composition. Then, through a systematic experimental-design procedure, certain reservoir and operational parameters are varied. By collecting results and analyzing a critical performance indicator from the simulation outputs, impacts of those parameters are analyzed. The final step is to construct a proxy model that can be used for screening purposes to assess the applicability in cases which were not necessarily studied using the numerical model.

\section{Methodology}

\subsection{Reservoir simulation model}

A single-well, compositional, single porosity reservoir with a Cartesian gridblock system is constructed using a commercial simulator (CMG 2013). To represent the component-mass flow from fractures into the matrix caused by compositional gradients, the molecular diffusion option for nitrogen (CMG 2013), which is a critical factor during the soaking period of cyclic pressure pulsing process, is

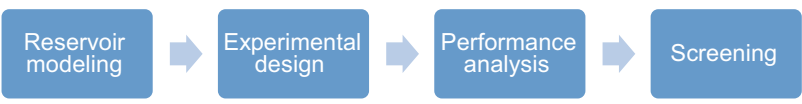

Fig. 2 The workflow followed to achieve the objectives of this study activated. Sigmund correlation for molecular diffusion (Sigmund 1976) is used with a diffusion coefficient for nitrogen of $0.001 \mathrm{~cm}^{2} / \mathrm{s}$, which is taken from the literature (Silva and Belery 1989) and validated with the ChapmanEnskog binary-diffusion theory (Marrero and Mason 1972).

The square-shaped model consists of 961 gridblocks and it has only one layer ( 31 blocks in the $x$ and $y$ directions, 1 block in the $z$ direction). There is a production/injection well at the center of the model. For the production well, the minimum bottom hole pressure is specified as 14.7 psia since the study focuses on fully or nearly depleted reservoirs with an average reservoir pressure of 50 psia. Injection constraints are defined as design parameters of the cyclic pressure pulsing process and varied during the study as explained in Sect. 2.2. The reservoir model is mainly characterized with properties from the Appalachian Basin sandstones (Duda et al. 1967; Boswell et al. 1993) that are shown in Table 1. Parameters that define the reservoir volume and initial conditions are kept constant, since the primary objective is to study the effects of other parameters that affect the flow dynamics such as the reservoir permeability and the hydraulic fracture characteristics.

The oil composition used is the Mid-Continent crude oil of $36^{\circ}$ API gravity (Abboud 2005) and it is shown in Table 2. Figure 3 shows the phase envelope of the oil mixture around the wellbore after injecting nitrogen into the Mid-Continent crude oil (Farias and Watson 2007). During the operating range of this study, $\left(70^{\circ} \mathrm{F}\right.$ and $50-500$ psia) the reservoir hydrocarbon-mixture is $100 \%$ in a liquid phase. Therefore, there is not any free gas other than the injected gas. Relative permeability curves for oilwater and gas-oil systems are shown in Fig. 4, which are taken from the commercial simulator used (CMG 2013),

Table 1 Reservoir characteristics of the Appalachian Basin sandstones and its single-well homogeneous reservoir model

\begin{tabular}{ll}
\hline Property & Value \\
\hline Porosity & 0.1 \\
Thickness, ft & 50 \\
Initial pressure, psia & 50 \\
Drainage area, acres & 220 \\
Water saturation & 0.5 \\
Gas saturation & 0 \\
Oil saturation & 0.5 \\
Original oil in place, MMSTB & 4.14 \\
Reservoir permeability ${ }^{\mathrm{a}}, \mathrm{mD}$ & 1 \\
Fracture permeability $^{\mathrm{a}}, \mathrm{mD}$ & 5,000 \\
Fracture half-length $^{\mathrm{a}}, \mathrm{ft}$ & 550 \\
Fracture width $^{\mathrm{a}}, \mathrm{ft}^{\mathrm{ft}}$ & 0.1 \\
\hline a ${ }^{2}$ & 5 arameters those were changed during different parts of the study
\end{tabular}


with the end-point saturations being consistent with Appalachian Basin characteristics (Boswell et al. 1993). Here $k_{\text {rw }}$ and $k_{\text {row }}$ are the relative permeability to water and oil, respectively, for the water-oil system; $k_{\text {rg }}$ and $k_{\text {rog }}$ are the relative permeability to gas and oil, respectively, for the

Table 2 Mid-Continent crude oil composition with an API gravity of $36^{\circ}$ (after Abboud 2005)

\begin{tabular}{lllllllll}
\hline Component & $\mathrm{N}_{2}$ & $\mathrm{C}_{1}$ & $\mathrm{C}_{2}$ & $\mathrm{C}_{3}$ & $i-\mathrm{C}_{4}$ & $i-\mathrm{C}_{5}$ & $\mathrm{C}_{6}$ & $\mathrm{C}_{7+}$ \\
\hline Molar fraction & 0.1 & 0.2 & 1.1 & 5.5 & 9.6 & 14.9 & 5.8 & 62.8 \\
\hline
\end{tabular}

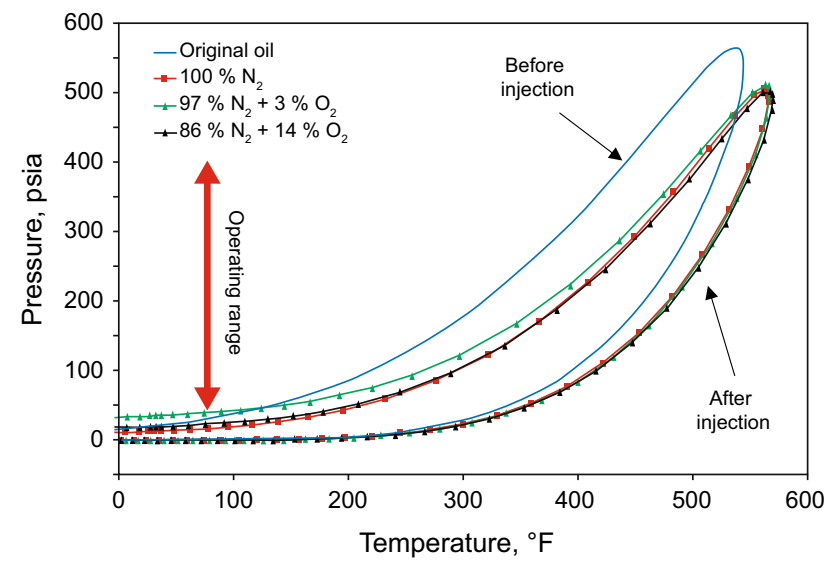

Fig. 3 Phase envelope of the oil mixture around the wellbore after injecting $\mathrm{N}_{2}$ into the Mid-Continent crude oil defined in the model (Farias and Watson 2007)

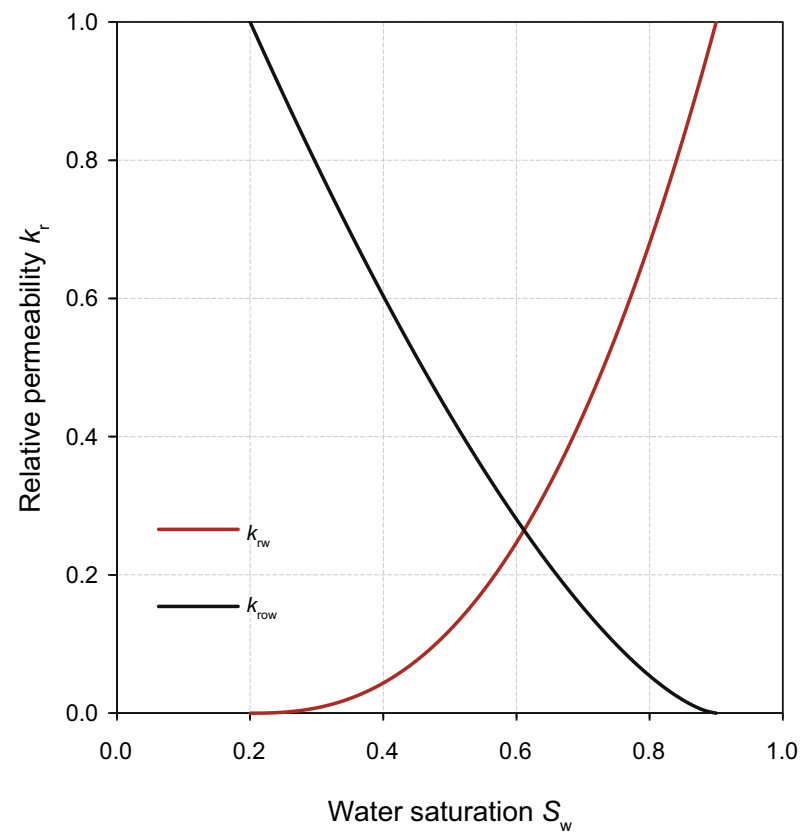

Fig. 4 Relative permeability curves used in the model gas-oil system. The production/injection well is hydraulically fractured, and the hydraulic fracture is represented as a high-permeability streak with a local-grid refinement to be able to capture the flow dynamics at the matrix-fracture interface (Fig. 5). A representative gas-saturation distribution during injection, after injection and after soaking around the hydraulic fracture is also seen in Fig. 5.

\subsection{Experimental design}

To design the simulation cases to run, an experimental design procedure is utilized which consists of selecting the parameters to be varied and selecting their ranges and levels. As a result, the parameters shown in Table 3 are selected which are divided into two groups as operational parameters and reservoir properties. Ranges of these parameters are selected with the objective of having reasonable uncertainties in each parameter. Hydraulic fracture parameters define the overall effectiveness of the fracturesystem to represent possible natural fractures around the wellbore that may contribute to the overall surface area for gas diffusion. It was decided to have five levels of variation in each variable. Normally, if the number of factors becomes moderately large, the number of runs may become unmanageable especially with the full-factorial design (Kelton and Barton 2003). However, in this case, a fullfactorial design was found to be achievable considering the CPU time of a single run, which is a function of the size and complexity of the reservoir model. Considering four variables and five levels, the total number of runs using a

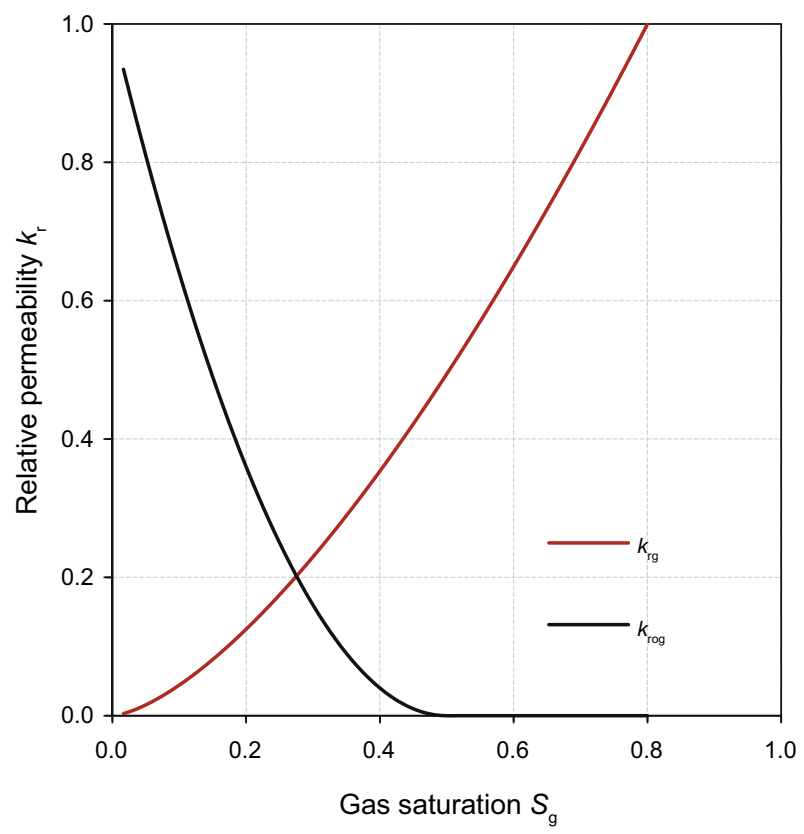




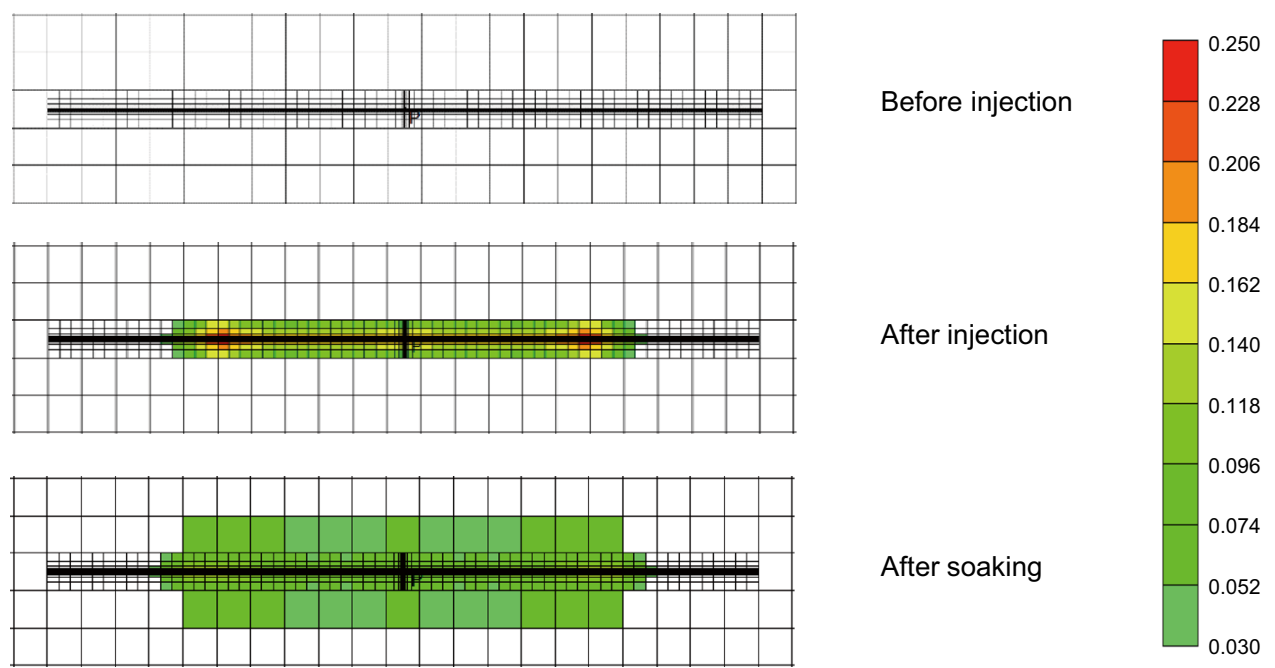

Fig. 5 Gas saturation during injection, after injection, and after soaking

Table 3 Parameters used with their ranges and levels as utilized in the experimental design procedure

\begin{tabular}{|c|c|c|c|c|c|c|c|c|c|c|}
\hline \multirow[t]{2}{*}{ Levels } & \multicolumn{5}{|c|}{ Operational parameters } & \multicolumn{5}{|c|}{ Reservoir/hydraulic fracture parameters } \\
\hline & 1 & 2 & 3 & 4 & 5 & 1 & 2 & 3 & 4 & 5 \\
\hline Injection rate, $\mathrm{MCF} /$ day & 40 & 80 & 120 & 160 & 200 & 120 & & & & \\
\hline Injection period, day & 10 & 25 & 50 & 75 & 100 & 50 & & & & \\
\hline Soaking period, day & 10 & 25 & 50 & 75 & 100 & 50 & & & & \\
\hline Cycle rate limit, STB/day & 1.0 & 2.0 & 3.0 & 4.0 & 5.0 & 3.0 & & & & \\
\hline Reservoir permeability, $\mathrm{mD}$ & 1 & & & & & 0.1 & 1 & 10 & 50 & 100 \\
\hline Fracture permeability, $\mathrm{mD}$ & 5000 & & & & & 1000 & 2500 & 5000 & 7500 & 10000 \\
\hline Fracture half length, ft & 550 & & & & & 150 & 350 & 550 & 750 & 1050 \\
\hline Fracture width, ft & 0.1 & & & & & 0.01 & 0.05 & 0.1 & 0.25 & 0.5 \\
\hline
\end{tabular}

full-factorial design would be equal to $625\left(5^{4}\right)$. Therefore, for both components of the study (operational and reservoir), the total number of simulation runs required is 1250 . As can be seen in Table 3, when the operational parameters are studied, reservoir and hydraulic fracture parameters are kept constant, and vice versa.

\subsection{Performance assessment}

Using the simulation model, the process performance is analyzed. The incremental oil production and the injected volume of gas are both incorporated into the assessment. The incremental production represents the additional oil produced on top of the base cumulative production that would have been achieved without the injection process (Prats 1982). The incremental oil produced $\left(N_{\text {pin }}\right)$ during year $n$ in STB is calculated as:

$N_{\mathrm{pi} n}=N_{\mathrm{pc} n}-N_{\mathrm{pb} n}$

where $N_{\mathrm{pc} n}$ is the cumulative recovery during year $n$ when cyclic injection is utilized (subscript $\mathrm{c}$ stands for cyclic injection), $\mathrm{STB} ; N_{\mathrm{pb} n}$ is the cumulative recovery during year $n$ when cyclic injection is not utilized (subscript b stands for base), STB. To represent the overall process performance, the discounted cyclic nitrogen injection efficiency is calculated by incorporating:

- Income generated from cumulative values of incremental oil produced,

- Costs due to nitrogen generation and injection,

- Time value of money through a discounting factor, $i$.

The present value of the incremental oil produced for 20 years of project time can be calculated from:

$N_{\mathrm{p} i 0}=\sum_{n=1}^{20} \frac{N_{\mathrm{pi} n}}{(1+i)^{n}}$

The present value of the cumulative volume of nitrogen injected can be calculated from:

$G_{\mathrm{i} 0}=\sum_{n=1}^{20} \frac{G_{\mathrm{i} n}}{(1+i)^{n}}$

where $G_{\mathrm{i}}$ is the cumulative volume of nitrogen injected during year $n ; i$ is the interest rate (taken as $10 \%$, yearly, 
in this study), and $n$ is the number of years (ranging between 1 and 20, for 20 years of project time). The performance indicator, discounted cyclic nitrogen-injection efficiency (in $\mathrm{STB} / \mathrm{MCF}$ ), is defined as:

$E_{\mathrm{c}}=\frac{N_{\mathrm{pi} 0}}{G_{\mathrm{i} 0}}$

which states the incremental volume of oil produced per MCF of gas injected. The economic efficiency can be calculated from:

$E_{\mathrm{ce}}=E_{\mathrm{c}} \times \frac{P_{\mathrm{o}}}{P_{\mathrm{N}_{2}}}$

where $P_{\mathrm{o}}$ is the oil price; $P_{\mathrm{N}_{2}}$ is the nitrogen price.

Assuming all other economic parameters are constant, this ratio can be used to identify if the project is feasible or not. Nitrogen generation cost is taken as $\$ 1 / \mathrm{MCF}$ of nitrogen for generating nitrogen from a polymeric membrane unit (Miller and Gaudin 2000; Artun et al. 2011a). Because the values are discounted, the numerator is representative of the time-zero value of additional income generated from the incremental oil production, and the denominator is the time-zero value of the cost associated with nitrogen generation and injection:

If $E_{\mathrm{ce}}>1$ then the net present value $N P V>0$

If $E_{\mathrm{ce}}<1$ then $N P V<0$

This efficiency parameter is not a substitute for a detailed economic analysis, but an indication and a quick estimation of whether the nitrogen generation/injection cost would be justified by the incremental oil produced. Therefore, it only includes the parameters that change from one case to another (i.e., how much money is spent on generating and injecting nitrogen, how much additional money is earned due to additional oil production). Since the same well is used for both injection and production, it is assumed that other operational costs, labor and expenses are not going to change during injection and production.

\subsection{Development of a screening tool}

This part of the study is aimed to develop a screening tool, to assess the performance of the cyclic nitrogen injection in a hydraulically fractured well in a computationally efficient manner. Intelligent systems have been applied to many different types of optimization problems in the petroleum industry. Most of these problems presented in the literature are based on the development of artificial neural network (ANN) based proxy models that can accurately mimic reservoir models within a reasonable amount of accuracy and computational efficiency. Artificial neural networks (ANN) are very powerful in extracting non-linear and complex relationships between input and output patterns. Several areas of application included reservoir characterization (Artun and Mohaghegh 2011; Raeesi et al. 2012; Alizadeh et al. 2012; Artun 2016), candidate well selection for hydraulic fracturing treatments (Mohaghegh et al. 1996), field development (Centilmen et al. 1999; Doraisamy et al. 2000; Mohaghegh et al. 1996), well-placement and trajectory optimization (Johnson and Rogers 2011, Guyaguler 2002; Yeten et al. 2003), scheduling of cyclic steam injection processes (Patel et al. 2005), screening and optimization of secondary/enhanced oil recovery (Ayala and Ertekin 2005; Artun et al. 2010, 2011b, 2012; Parada and Ertekin 2012; Amirian et al. 2013), history matching (Cullick et al. 2006; Silva et al. 2007; Zhao et al. 2015), underground-gas-storage management (Zangl et al. 2006), reservoir monitoring and management (Zhao et al. 2015; Mohaghegh et al. 2014), and modeling of shale-gas reservoirs (Kalantari-Dhaghi et al. 2015; Esmaili and Mohaghegh 2015).

In this study, the backpropagation algorithm is used to train the neural network. The backpropagation algorithm is a gradient-descent method that minimizes the error during the training process. A given set of inputs is mapped into a set of given outputs which classifies this training algorithm as a supervised training algorithm (Fausett 1994). The training process includes 3 stages:

(1) Feed-forward of the input training pattern,

(2) Calculation and back-propagation of the error,

(3) Adjustment of weights.

In Fig. 6, a fully-connected neural network with one hidden layer is shown. Number of input, hidden, and output neurons are $n, p$, and $m$, respectively. The number of inputs and outputs depend on the problem studied and the objective of the developed neural network, which both require knowledge of the subject-matter. The number of hidden neurons and hidden layers are determined as a part of the design process carried out for the neural network. Although there is not a straight-forward recipe for determining the number of hidden layers and neurons, they typically depend on the complexity of the problem as defined by the number of parameters and training patterns involved. There are a number of rules of thumb presented in the literature to determine the number of hidden neurons, and one of them is the following (Neuroshell 1998):

$p=\frac{n+m}{2}+\sqrt{N_{\mathrm{TP}}}$

where $N_{\mathrm{TP}}$ is the number of training patterns. It should be noted that this equation was developed mostly based on experience and should not be assumed to provide the correct number of hidden neurons for a given problem. However, it can be used as a good start for the optimization 


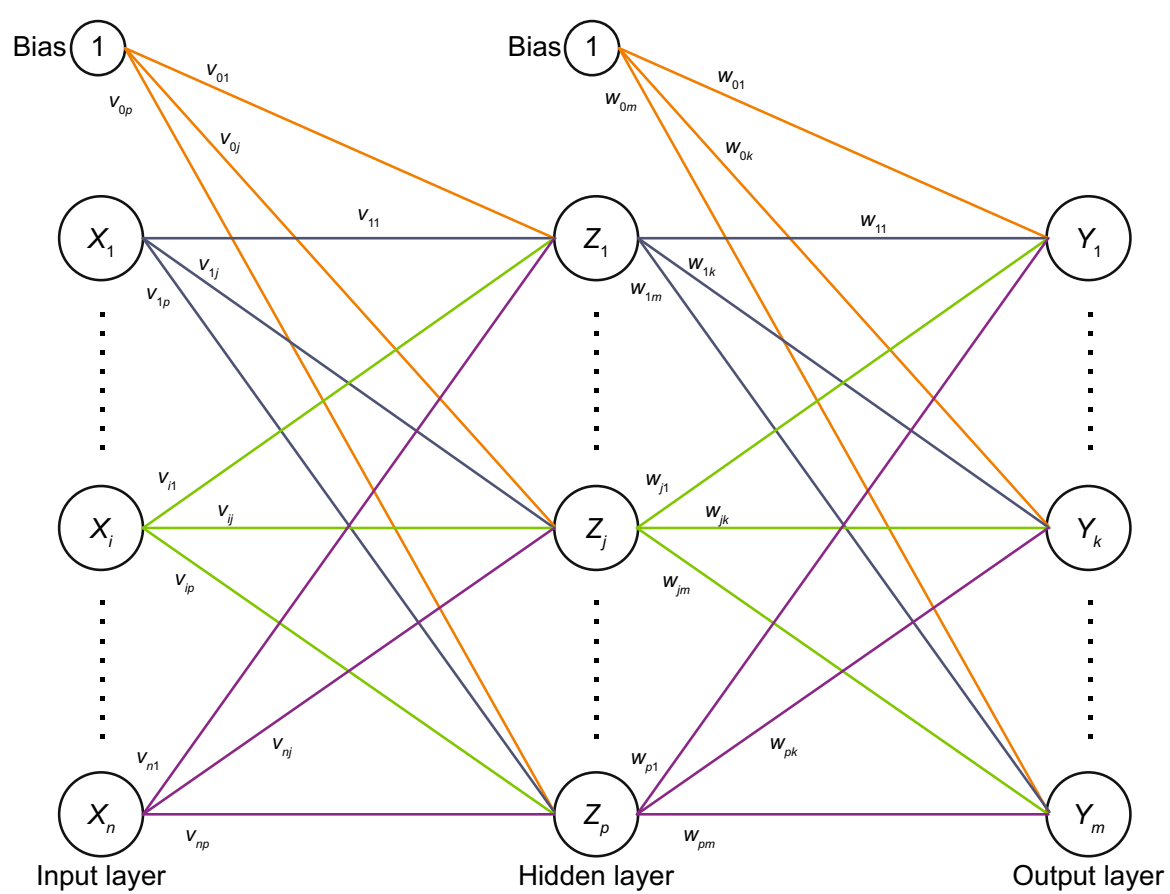

Fig. 6 Architecture of a multilayer network (after Artun 2016)

process. A step-by-step explanation of the backpropagation algorithm is shown below and more details about the terms involved can be found in any book on artificial neural networks such as (Fausett 1994): squared error is calculated and iterations continue until the stopping criteria is satisfied. Most common stopping criteria include achieving the minimum mean-squared error or maximum number of epochs. After training is completed,

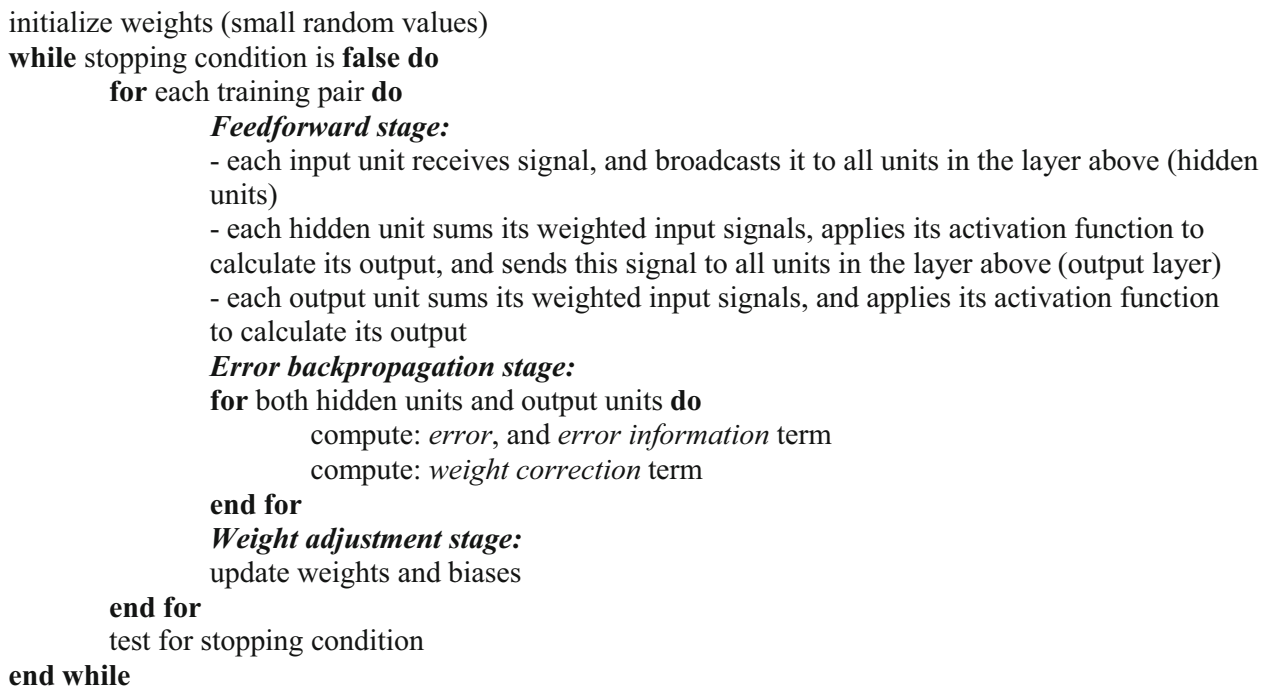

The inner iterative loop shown in this algorithm is repeated for all training cases included in the training set. When all training cases are processed once, one epoch is completed. After each training iteration, the average mean- the weights on connection links achieve their optimum states. If the training performance is satisfactory, and if the model is validated with realistic, representative cases, then the trained network can be used as a predictive model. In 
this study, mapping input-output relationships is achieved with the inputs of operational and reservoir/hydraulic fracture characteristics, and the output of the cyclic nitrogen injection efficiency.

After running all cases and collecting corresponding performance indicators using the numerical model, a knowledge base is obtained. This knowledge base is then fed into an ANN, which has characteristics that have been pre-determined, for training. Once being trained and validated it is expected that the ANN-based proxy model can provide responses within comparable accuracy to a numerical model. Such kind of a model can be used as a screening tool for the cyclic pressure pulsing process with nitrogen, for cases that have not been necessarily run using the numerical model. This workflow is summarized in Fig. 7. In this study, the input parameters are the operational and reservoir/hydraulic fracture parameters as shown in Table 3, and the critical performance indicator is the discounted cyclic-nitrogen-injection efficiency, $E_{\mathrm{c}}$. defined in Eq. (4).

\section{Results and discussion}

\subsection{Analysis of operational parameters}

In this part of the study, the reservoir parameters are kept constant as shown in Table 3. Matrix permeability of $1 \mathrm{mD}$ is representative of sandstone reservoirs of the Appalachian Basin. Hydraulic fracture properties are the mid-levels of the levels used in the 2nd part of the study.

\subsubsection{An overview of results}

Minimum and maximum efficiencies obtained among all cases are shown in Table 4. It is observed that in all cases

\begin{tabular}{cccc}
$\begin{array}{c}\text { Injection rate, } \\
\text { MCF/d }\end{array}$ & $\begin{array}{c}\text { Injection period, } \\
\mathrm{d}\end{array}$ & $\begin{array}{c}\text { Soaking period, } \\
\mathrm{d}\end{array}$ & $\begin{array}{c}\text { Production period, } \\
\text { months }\end{array}$ \\
\hline 50 & 100 & 50 & 12 \\
100 & 25 & 100 & 6 \\
75 & 75 & 25 & 3 \\
150 & 50 & 75 & 9 \\
$\vdots$ & $\vdots$ & $\vdots$ & $\vdots$ \\
100 & 25 & 25 & 12
\end{tabular}

1. Construct a data-base of the parameters to be studied within the ranges of the study

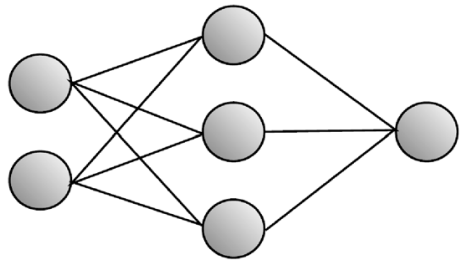

4. Design an artificial neural network and train the neural network by feeding the knowledge base as the training data.

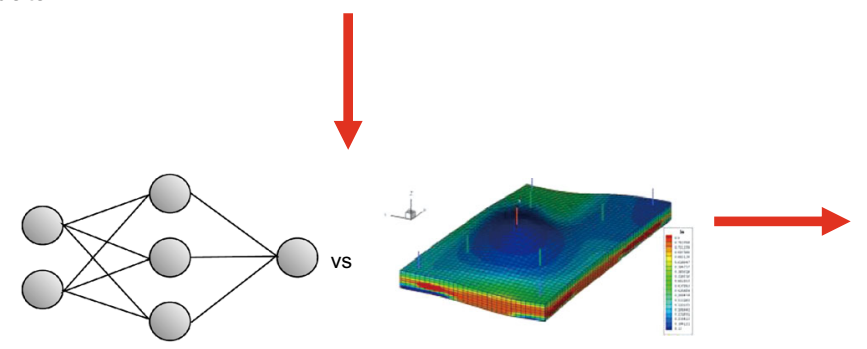

5. Validate the generalization capabilities of the trained neural network by testing with representative blind cases.

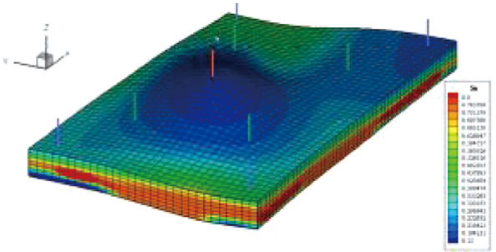

2. Construct a representative numerical reservoir model for the problem studied, and run the model for each case defined in Step 1.

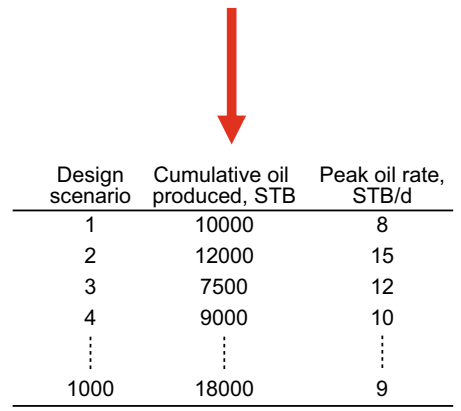

3. Collect the corresponding performance indicators in a knowledge base.

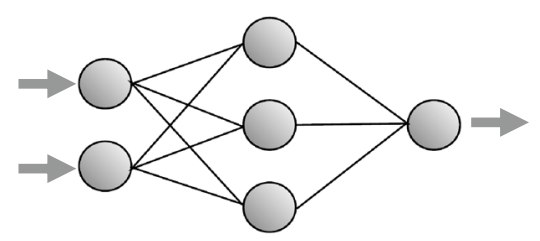

6. Use the trained neural network as a ANN-based proxy model for screening purposes.

Fig. 7 Workflow for constructing an ANN-based proxy model that can be used as a screening tool (after Artun et al. 2012) 
Table 4 Minimum and maximum discounted efficiencies obtained when the operational parameters are varied

\begin{tabular}{lllllr}
\hline & Injection rate, MCF/day & Injection period, day & Soaking period, day & Cycle rate limit, STB/day & Efficiency, STB/MCF \\
\hline Min. & 200 & 100 & 50 & 5.0 & 0.9 \\
Max. & 40 & 10 & 75 & 5.0 & 14.4 \\
\hline
\end{tabular}

the efficiency is greater than 0 . This means that discounted oil production with nitrogen injection is always greater than cases without injection, which resulted in an incremental production of greater than zero. Since the cost of nitrogen generation is $\$ 1 / \mathrm{MCF}$, the minimum efficiency of $0.9 \mathrm{STB} / \mathrm{MCF}$ indicates that the economic efficiency would be greater than 1 as long as the oil price is greater than $\$ 1.1 / \mathrm{STB}$. Therefore, for almost any realistic oil price scenario, the 20-year cyclic nitrogen injection project would be feasible within the operational ranges studied.

\subsubsection{Analysis of top 100 cases}

Cases with the highest 100 efficiencies are analyzed to develop an understanding of ranges of variables that are favorable. Histograms that show the number of occurrences for all variables are plotted. Histograms for injection rate and period for top 100 discounted cyclic nitrogen injection efficiencies are shown in Fig. 8a, b. Results show that most of the top cases $(87 \%)$ have a nitrogen injection rate less than or equal to $120 \mathrm{MCF} /$ day and $93 \%$ of cases have an injection period of less than or equal to 25 days. The injected volume of nitrogen can be calculated by multiplying injection rate and time. Figure $8 \mathrm{c}$ shows the histogram of injection volume for top 100 discounted efficiencies. It is seen that $99 \%$ of the cases have injection volumes less than $2000 \mathrm{MCF}$ per cycle. These results indicate that nitrogen injection should be kept at the lower ranges that are studied. This may be due to the blockage of flow paths into the hydraulic fractures when higher volumes are injected and relative permeability effects. On the contrary, in the case of naturally fractured reservoirs, there is an interconnected network of fractures that enables easier flow of both gas and oil and higher volumes of gas contributes to higher oil recovery (Artun et al. 2011a). Longer injection periods may affect the process negatively because of dissipation of pressure with time. Therefore, these results show that it is critical to optimize the injection rate, period and volume. Figure $8 \mathrm{~d}$ shows the histogram of soaking period for the top 100 cases. It is observed that for $72 \%$ of the cases, the soaking period is greater than or equal to 50 days. Therefore, longer soaking periods favor the efficiency of the process. It is known from earlier studies that the typical soaking period needed for naturally fractured reservoirs is around 2-4 weeks. Therefore, a much longer time is necessary for a hydraulically fractured well than a naturally fractured system. This is due to the smaller contact area for the gas diffusion in a hydraulically fractured well, when there is not a naturally fractured system that has an extensive contact area for the injected gas. Figure 8e shows the histogram of cycle rate limit for the top 100 cases. It is seen that $96 \%$ of the cases realized with $2 \mathrm{STB} /$ day of economic limit or more to stop the production and start the injection. The case that there are only 4 cases with $1 \mathrm{STB} /$ day highlights the necessity of existing reservoir energy for the process to be successful. While there is not a clear indication of the optimum rate to stop the production between 2 and $5 \mathrm{STB} /$ day, the potential risk of losing production time should be noted for higher rates. Amount of production lost by stopping early may not be compensated by the additional production due to injection. Figure $8 \mathrm{f}$ shows the total production shut-in time (injection and soaking periods). In this histogram, the maximum number of occurrences is when the time is between 50 and 100 days and less optimum results when the time is less than 50 days and greater than 100 days. This shows that there must be sufficient time of injection and soaking to maximize the process efficiency. However, when the time is too long, the process is clearly affected negatively with no cases above 150 days of shut-in time. This is due to dissipation of the pressure increase by injection at longer periods of time. This highlights another important parameter, the total duration of shut-in, for optimization.

\subsubsection{Analysis of all cases}

For further analysis, all cases are analyzed by taking the arithmetic average of all levels for each parameter and generating a 2-dimensional table of the averaged values. Figure 9 shows these values with respect to cycle rate limit and injection volume. The results indicate a lower range of injection volumes per cycle is more favorable for the efficiency of the process. This is probably due to the fact that lost production time is not compensated by the incremental oil produced. The low-permeability nature of the reservoir system does not allow gas to be transported into further portions of the reservoir, and therefore fails to displace more volume of oil from the matrix system. When we analyze the cycle rate limit, it is observed that rates higher than or equal to $2 \mathrm{STB} / \mathrm{day}$ are favorable. This indicates that existing reservoir energy in the system is 

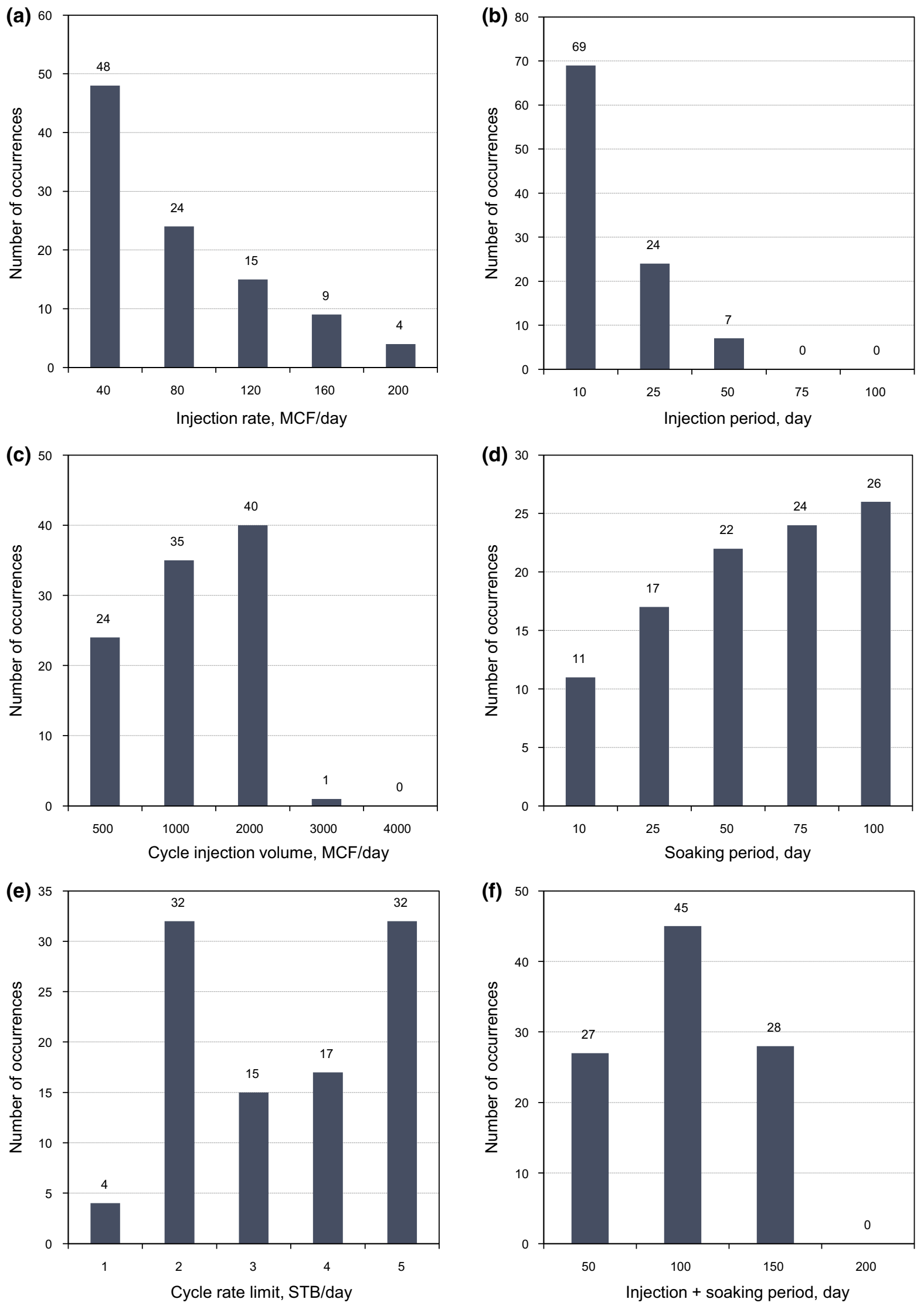
Fig. 8 Histogram of operational parameters for top 100 runs in terms of the process efficiency

critical for the efficiency. Therefore, while the existing energy is critical, shutting in the well for long times when the well is still producing at reasonable rates is not a good practice. This is seen with the wide-range of the low-efficiency area when the limit is 5 STB. However, it should be noted that the best performers are with minimum injection volume and maximum cycle rate limit $(400 \mathrm{MCF}$, and 5 STB/day). In Fig. 10, the efficiency values are mapped with respect to soaking and injection period lengths. The same observations with the top 100 cases also hold in this case. A soaking period is required and longer soaking periods improve the efficiency almost up to $28 \%$ for 10 day of injection period. When the injection period is 100 days, since most of soaking already realized during the injection period itself, the improvement is very small (only $12 \%)$.

\subsection{Analysis of reservoir/hydraulic fracture parameters}

In this part of the study, the operational parameters are kept constant and reservoir and hydraulic fracture properties are varied. The injection rate is $120 \mathrm{MCF} /$ day, injection and soaking periods are 50 days, and the economic rate limit for oil production is $3 \mathrm{STB} /$ day.

\subsubsection{An overview of results}

Minimum and maximum efficiencies obtained among all cases are shown in Table 5. It is observed that in all cases the efficiency is greater than 0 . This means that discounted oil production with nitrogen injection is always greater than cases without gas injection. Since the cost of nitrogen generation/injection is $\$ 1 / \mathrm{MCF}$, the minimum efficiency of 0.4 STB/MCF indicates that economic efficiency would be greater than one as long as the oil price is greater than $\$ 2.50 / \mathrm{STB}$. Therefore, for almost any realistic oil price scenario, the 20-year cyclic nitrogen injection project will generate a net present value greater than zero within the operational ranges studied.

\subsubsection{Analysis of top 100 cases}

Cases with highest 100 efficiencies are analyzed to develop an understanding of ranges of variables that are favorable. Histograms that show the number of occurrences for all variables are plotted. Histograms for matrix permeability, fracture permeability, fracture width, and half-length are shown in Fig. 11. These results indicate that matrix

\begin{tabular}{|c|c|c|c|c|c|c|c|}
\hline & \multirow{2}{*}{$E_{\mathrm{c}}$} & \multicolumn{5}{|c|}{ Cycle rate limit, STB/day } & \multirow[b]{2}{*}{ Average } \\
\hline & & 1 & 2 & 3 & 4 & 5 & \\
\hline \multirow{17}{*}{ 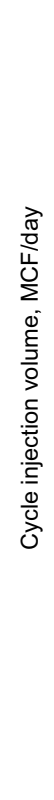 } & 400 & 3.8 & 5.2 & 4.9 & 8.4 & 11.9 & 6.8 \\
\hline & 800 & 3.3 & 4.5 & 4.3 & 5.0 & 7.9 & 5.0 \\
\hline & 1000 & 3.1 & 5.0 & 3.7 & 6.3 & 7.7 & 5.2 \\
\hline & 1200 & 2.9 & 4.2 & 4.2 & 3.9 & 5.9 & 4.2 \\
\hline & 1600 & 2.8 & 3.9 & 3.4 & 3.0 & 5.0 & 3.6 \\
\hline & 2000 & 2.7 & 3.8 & 3.1 & 2.7 & 3.9 & 3.2 \\
\hline & 3000 & 2.8 & 3.5 & 3.0 & 2.5 & 2.4 & 2.8 \\
\hline & 4000 & 2.6 & 3.0 & 2.6 & 2.2 & 2.1 & 2.5 \\
\hline & 5000 & 2.4 & 2.7 & 2.6 & 2.2 & 1.8 & 2.3 \\
\hline & 6000 & 2.1 & 2.3 & 2.2 & 1.9 & 1.7 & 2.1 \\
\hline & 8000 & 1.7 & 2.1 & 1.9 & 1.6 & 1.4 & 1.7 \\
\hline & 9000 & 1.7 & 2.1 & 1.8 & 1.5 & 1.3 & 1.7 \\
\hline & 10000 & 1.6 & 2.0 & 1.7 & 1.5 & 1.2 & 1.6 \\
\hline & 12000 & 1.4 & 1.7 & 1.5 & 1.4 & 1.2 & 1.4 \\
\hline & 15000 & 1.3 & 1.5 & 1.4 & 1.3 & 1.1 & 1.3 \\
\hline & 16000 & 1.2 & 1.5 & 1.4 & 1.2 & 1.0 & 1.3 \\
\hline & 20000 & 1.1 & 1.2 & 1.2 & 1.1 & 1.0 & 1.1 \\
\hline & Average & 2.3 & 2.9 & 2.6 & 2.6 & 3.1 & \\
\hline
\end{tabular}

Fig. 9 Average values of efficiencies of all cases with respect to the cycle rate limit and injection volume 


\begin{tabular}{|c|c|c|c|c|c|c|c|}
\hline & \multicolumn{3}{|c|}{$\begin{array}{l}28 \% \text { higher efficiency with soaking } \\
\text { for } 100 \text { days than soaking for } 10 \text { day }\end{array}$} & & \multicolumn{3}{|c|}{$\begin{array}{l}\text { Dissipation of pressure with long } \\
\text { injection time (too late for soaking) }\end{array}$} \\
\hline & \multirow{2}{*}{$E_{\mathrm{c}}$} & \multicolumn{4}{|c|}{ Injection period, day } & $\nabla$ & \multirow[b]{2}{*}{ Average } \\
\hline & & 10 & 25 & 50 & 75 & 100 & \\
\hline \multirow{6}{*}{ 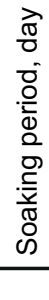 } & 10 & 3.7 & 2.8 & 2.0 & 1.8 & 1.5 & 2.4 \\
\hline & 25 & 4.3 & 3.1 & 2.2 & 1.9 & 1.6 & 2.6 \\
\hline & 50 & 4.9 & 3.3 & 2.3 & 1.9 & 1.6 & 2.8 \\
\hline & 75 & 4.9 & 3.5 & 2.3 & 1.9 & 1.6 & 2.8 \\
\hline & 100 & 5.1 & 3.4 & 2.4 & 1.9 & 1.7 & 2.9 \\
\hline & Average & 4.6 & 3.2 & 2.2 & 1.9 & 1.6 & \\
\hline
\end{tabular}

Fig. 10 Average values of efficiencies of all cases with respect to soaking and injection periods

Table 5 Minimum and maximum discounted efficiencies obtained when reservoir/hydraulic-fracture parameters are varied

\begin{tabular}{llllll}
\hline & Matrix permeability, $\mathrm{mD}$ & Fracture permeability, $\mathrm{mD}$ & Fracture width, $\mathrm{ft}$ & Fracture half-length, ft & Efficiency, STB/MCF \\
\hline Min. & 0.1 & 7500 & 0.05 & 150 & 0.4 \\
Max. & 10 & 10,000 & 0.5 & 750 & 3.2 \\
\hline
\end{tabular}

permeability is very critical such that range of permeability between 10 and $100 \mathrm{mD}$ constitutes $98 \%$ of the cases. While higher fracture permeabilities are favorable, their impact is not as large as the matrix permeability. This is probably due to the permeability difference between the fracture and the matrix and its contribution to the diffusion process. The reason that there is not an observable difference between 10, 50 and $100 \mathrm{mD}$, is due to the high-base recovery of high permeability reservoirs. Since the base recoveries are high, the amount of incremental recovery that could be achieved with injection is also reduced. Effective fracture width values greater than $0.01 \mathrm{ft}$ (between 0.05 and $0.5 \mathrm{ft}$ ) are favorable, while $80 \%$ of cases are $0.25 \mathrm{ft}$ or more. For the fracture half-length, we would expect that longer fractures would provide better efficiency because of the greater surface area for gas diffusion. The results indicate that $85 \%$ of the cases are with half-lengths of 550 or $1050 \mathrm{ft}$.

\subsubsection{Analysis of all cases}

Figure 12 shows average efficiency values with respect to matrix and fracture permeabilities. A similar observation with the top 100 cases is the fact that matrix permeabilities of $10 \mathrm{mD}$ and higher result in higher efficiencies. It is also observed that the efficiency is not a strong function of fracture permeability but an effective fracture permeability of $10,000 \mathrm{mD}$ can increase the efficiency by $25 \%$ when compared with $1000 \mathrm{mD}$. This indicates that as long as there is a fracture, the diffusion process helps to displace the oil in the matrix. For higher matrix permeabilities of 50 and $100 \mathrm{mD}$, the base recovery is high and the efficiency does not change significantly from 1 or $10 \mathrm{mD}$ reservoirs. A tight-reservoir permeability of $0.1 \mathrm{mD}$ is also less effective than that of a permeability of $1-10 \mathrm{mD}$. This indicates that the Appalachian Basin sandstones would be good candidates for cyclic nitrogen injection. Figure 13 is a similar plot with the effective fracture width and fracture half length. As long as the fracture width is greater than $0.01 \mathrm{ft}$, and fracture half-length is greater than $150 \mathrm{ft}$, the process efficiency appears to be more favorable. This is due to the increased surface area for diffusion with an effective hydraulic fracture. Results indicated that with the same operational parameters, hydraulic fracture effectiveness can double the efficiency.

\subsection{Screening tool}

An ANN with an architecture shown in Fig. 14 is constructed. In this neural network, there are 12 input parameters, with six of them represent operational parameters, and remaining six parameters represent reservoir and hydraulic fracture parameters. In addition to the base parameters determined in the previous stages of the study, 4 additional parameters are added which are functions of the base parameters to help represent the problem in an improved way. These include: 

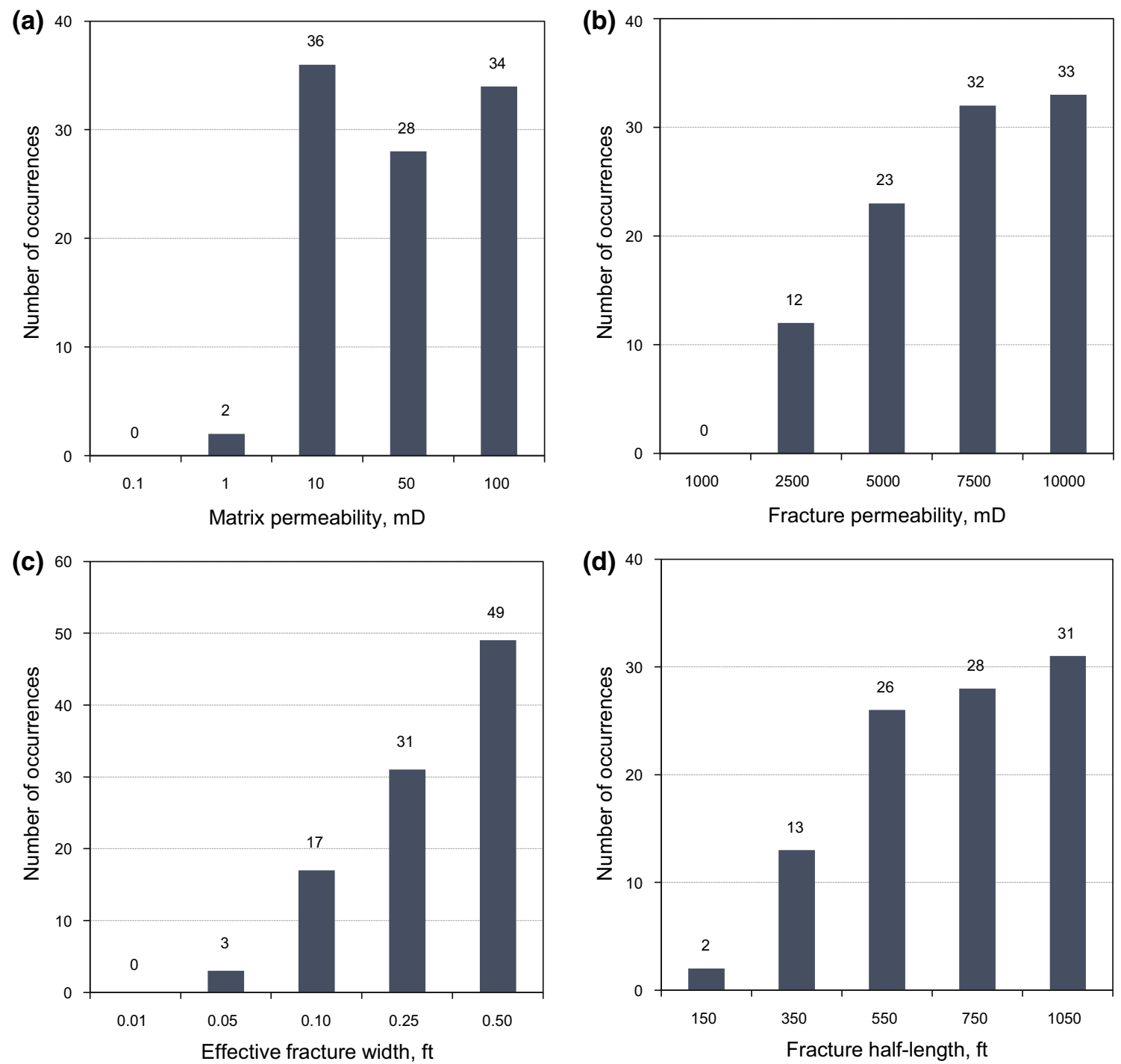

Fig. 11 Histogram of reservoir parameters for top 100 runs in terms of the process efficiency

(1) $t_{\mathrm{i}}+t_{\mathrm{s}}$ : summation of injection and soaking periods to account for the total amount of time in each cycle during which the well is not on production,

(2) $G_{\mathrm{i}}$ : multiplication of injection period with injection rate to account for the volume of gas injected in each cycle,

(3) $A_{\mathrm{f}}$ : multiplication of fracture length with fracture width to account for the effective size of the fracture,

(4) $k_{\mathrm{f}} / k_{\mathrm{m}}$ : ratio of fracture permeability to the matrix permeability to account for the contrast between matrix and fracture permeabilities.

The only output is the discounted cyclic-injection efficiency, $E_{\mathrm{c}}$. Considering the size of the problem (1250 patterns, 12 inputs and 1 output), a single-hidden-layer network with 50 neurons is constructed (Fig. 14). A Levenberg-Marquardt backpropagation algorithm is used for training (MATLAB 2013a), with a hyperbolic tangent sigmoid transfer function between input-hidden layers, and a linear transfer function between hidden and output layers. Among 1250 patterns $70 \%$ of the dataset is used for training (874 cases), $15 \%$ (188 cases) is used for validation during training to prevent over-training problems, and remaining $15 \%$ (188 cases) used for blindtesting purposes to test the generalization capabilities of the trained neural network. The full set of characteristics of the neural network is shown in Table 6 .

The training is terminated after 200 validation checks without improvement after 213 epochs. The training error was $0.5 \%$. The trained neural network is applied to the whole data set, and to the training, validation, and testing sets separately. Figure 15 shows the cross-plots of results obtained from the numerical model and the ANN-proxy model. These comparisons indicate the proxy model has high-accuracy prediction capability, with a correlation 


\begin{tabular}{|c|c|c|c|c|c|c|c|}
\hline & \multicolumn{3}{|c|}{ Too tight } & \multicolumn{4}{|c|}{ High base recovery } \\
\hline & \multirow{2}{*}{$E_{\mathrm{c}}$} & \multicolumn{5}{|c|}{ Matrix permeability, $\mathrm{mD}$} & \\
\hline & & 0.1 & 1 & 10 & 50 & 100 & Average \\
\hline \multirow{6}{*}{ 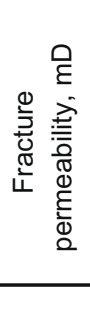 } & 1000 & 0.6 & 1.6 & 1.9 & 1.9 & 1.9 & 1.6 \\
\hline & 2500 & 0.7 & 1.8 & 2.2 & 2.1 & 2.1 & 1.8 \\
\hline & 5000 & 0.8 & 1.9 & 2.3 & 2.3 & 2.4 & 1.9 \\
\hline & 7500 & 0.8 & 2.0 & 2.4 & 2.4 & 2.4 & 2.0 \\
\hline & 10000 & 0.8 & 2.0 & 2.5 & 2.4 & 2.5 & 2.0 \\
\hline & Average & 0.7 & 1.8 & 2.2 & 2.2 & 2.3 & \\
\hline
\end{tabular}

Fig. 12 Average values of efficiencies of all cases with respect to matrix permeability and fracture permeability

\begin{tabular}{|c|c|c|c|c|c|c|c|}
\hline & \multirow{2}{*}{$E_{\mathrm{c}}$} & \multicolumn{5}{|c|}{ Effective fracture width, $\mathrm{ft}$} & \multirow[b]{2}{*}{ Average } \\
\hline & & 0.01 & 0.05 & 0.1 & 0.25 & 0.5 & \\
\hline \multirow{5}{*}{ 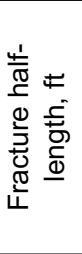 } & 150 & 1.2 & 1.4 & 1.4 & 1.6 & 1.7 & 1.5 \\
\hline & 350 & 1.4 & 1.7 & 1.8 & 1.9 & 2.1 & 1.8 \\
\hline & 550 & 1.5 & 1.9 & 2.1 & 2.2 & 2.3 & 2.0 \\
\hline & 750 & 1.5 & 1.9 & 2.1 & 2.2 & 2.4 & 2.0 \\
\hline & 1050 & 1.5 & 1.9 & 2.1 & 2.2 & 2.3 & 2.0 \\
\hline & Average & 1.4 & 1.8 & 1.9 & 2.0 & 2.2 & \\
\hline
\end{tabular}

Hydraulic fracture effectiveness can double the process efficiency (from 1.2 to $2.4 \mathrm{STB} / \mathrm{MCF}$ )

Fig. 13 Average values of efficiencies of all cases with respect to effective fracture width and fracture half-length

coefficient of 0.96 for the testing set, which is the set that was not shown during training. In Fig. 16, the histogram of the calculated errors is shown. For the efficiency range of $0-14.4$, the fact that the great majority of the cases have an error less than $0.5 \mathrm{STB} / \mathrm{MCF}$ also highlights the high predictive capability of the trained neural network. Therefore, this model can be used for screening of the cyclic nitrogen injection process for a well with hydraulic fractures, when the quantities of specified operational and reservoir/hydraulic fracture parameters are provided. This helps the practicing reservoir engineer or manager to evaluate a large number of different scenarios and obtain expected process efficiency in a quick and practical manner.

\section{Conclusions}

The purpose of this study was to develop a better understanding of how operational and reservoir/hydraulic-fracture parameters affect the performance of the cyclic nitrogen injection in hydraulically fractured wells. This is achieved by building and running a numerical reservoir simulation model. The reservoir fluid is characterized with a Mid-Continent crude oil that can be considered as volatile. By extending the range of certain reservoir properties, a generalized analysis is also carried out. Experimental design methodology is followed to analyze the outcomes of the wide ranges of the properties studied. A screening tool is developed by training a neural network with the knowledge base obtained with the simulation runs. The principal conclusions drawn from this study can be summarized as the following:

(1) Within the ranges studied, considering a cost of $\$ 1 /$ MCF for nitrogen generation, cyclic injection of nitrogen is a feasible enhanced oil recovery method in hydraulically fractured wells, especially in the Appalachian Basin.

(2) The economic rate limit for stopping the production and starting the injection must be optimized. The 


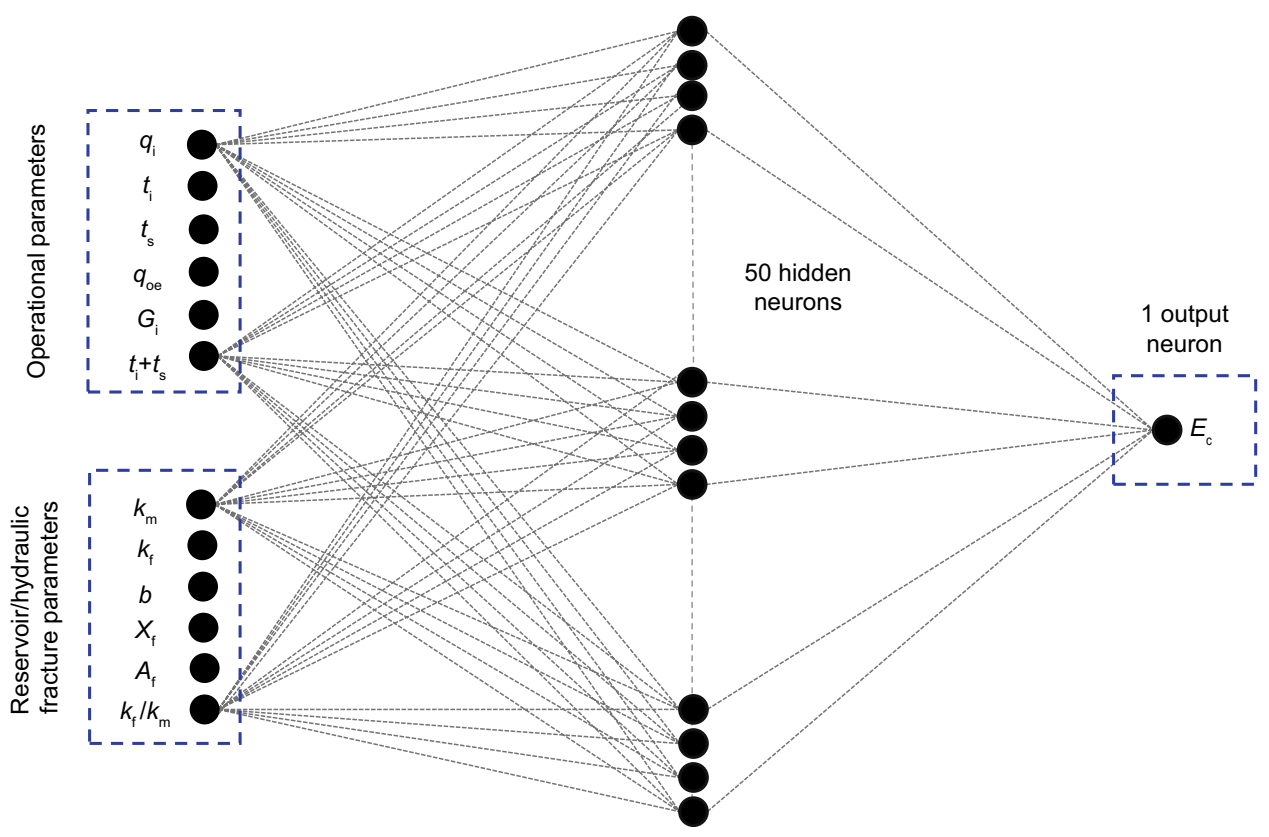

Fig. 14 Architecture of the ANN developed. $q_{\mathrm{i}}$ is the injection rate, MCF/day; $t_{\mathrm{i}}$ is the length of the injection period length, $\mathrm{d} ; t_{\mathrm{s}}$ is the length of the soaking period length, $\mathrm{d} ; q_{\mathrm{oe}}$ is the economic rate limit for each cycle, STB/day; $G_{\mathrm{i}}$ is the volume of gas injected in each cycle, MCF; $k_{\mathrm{m}}$ is the matrix permeability, $\mathrm{mD} ; k_{\mathrm{f}}$ is the fracture permeability, $\mathrm{mD} ; b$ is the effective fracture width, $\mathrm{ft} ; X_{\mathrm{f}}$ is the effective fracture half-length, $\mathrm{ft}$; $A_{\mathrm{f}}$ is the effective areal size of the fracture, $\mathrm{ft}^{2}$

Table 6 Characteristics of the constructed artificial neural network

\begin{tabular}{ll}
\hline Property & Value \\
\hline No. of input neurons & 12 \\
No. of hidden layers and neurons & 1 hidden layer with 50 neurons \\
No. of output neurons & 1 \\
Training algorithm & Levenberg-Marquardt backpropagation \\
Transfer function between input and hidden layers & Hyperbolic tangent sigmoid \\
Transfer function between hidden and output layers & Linear \\
Training set, \% & 70 \\
Validation set, \% & 15 \\
Testing set, \% & 15 \\
Max. No. of epochs & 10,000 \\
Min. error, \% & 0.0001 \\
Max. No. of iterations without improvement & 200
\end{tabular}

amount of existing energy in the reservoir is important for successful application. When the production is stopped at higher rates, the injection and soaking time should be kept to a minimum so not to lose production time that cannot be recovered with the help of injection.

(3) A soaking period is necessary to allow for gas diffusion, but together with the injection period, the optimum time must be determined as long shut-in periods (longer than $100 \mathrm{~d}$ ) cause dissipation of pressure after injection.
(4) Matrix permeability is very critical such that permeabilities of $10 \mathrm{mD}$ and higher result in more favorable results. The fracture permeability affects the process less than the matrix permeability, and an effective fracture permeability can increase the efficiency by $25 \%$.

(5) Longer $(>150 \mathrm{ft})$ and wider $(>0.01 \mathrm{ft})$ fractures provide better efficiency because of the greater surface area for gas diffusion. With the same operating conditions, hydraulic-fracture effectiveness can double the efficiency. 
(a)

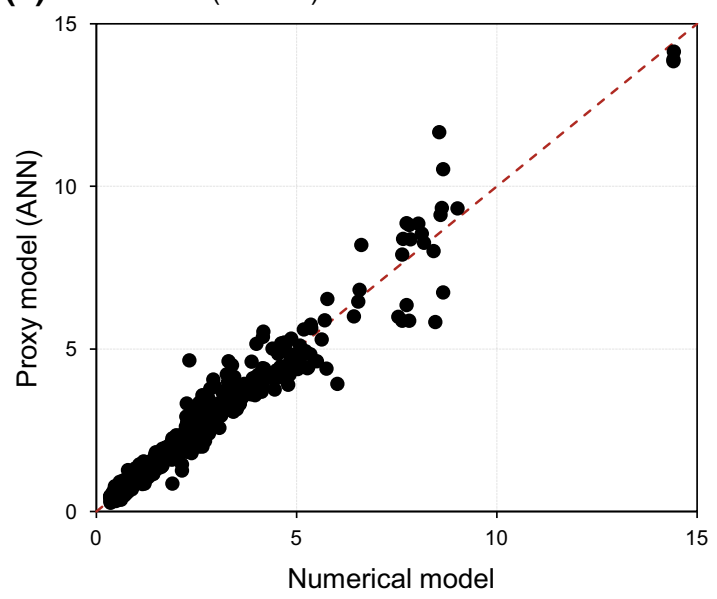

(c) Validation set $(R=0.94)$

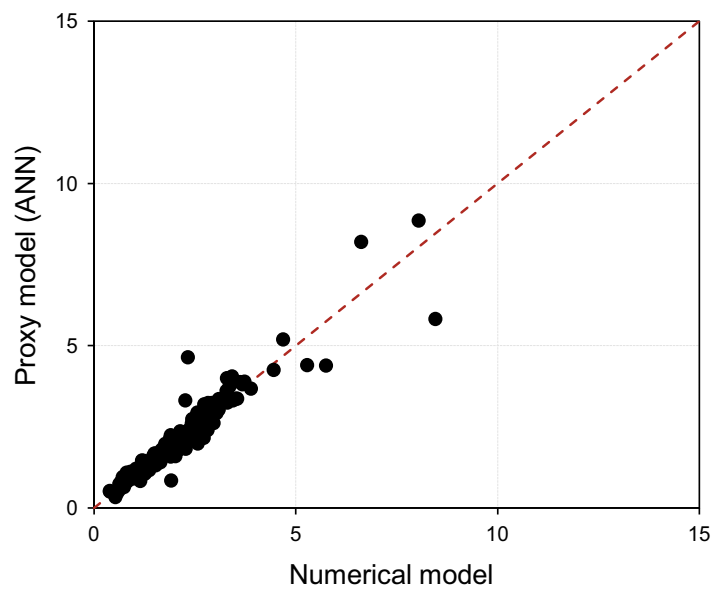

(b) Training set $(R=0.98)$

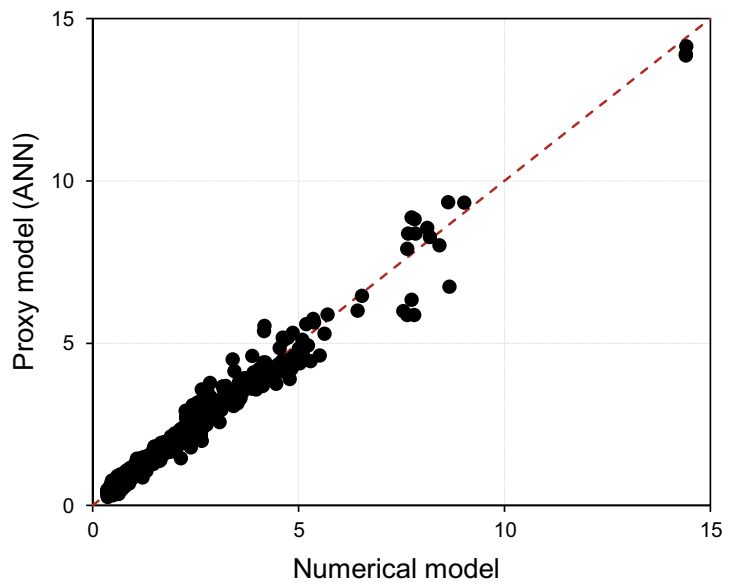

(d) Testing set $(R=0.96)$

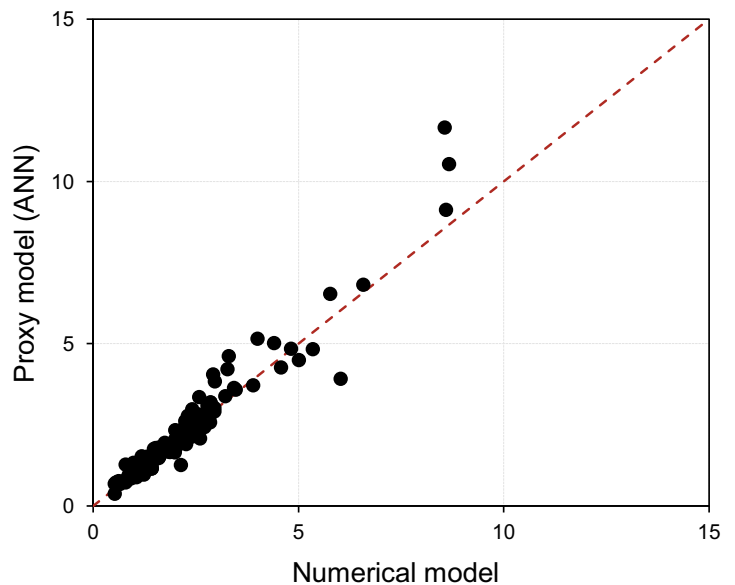

Fig. 15 Accuracy of ANN predictions for training, validation, and testing sets

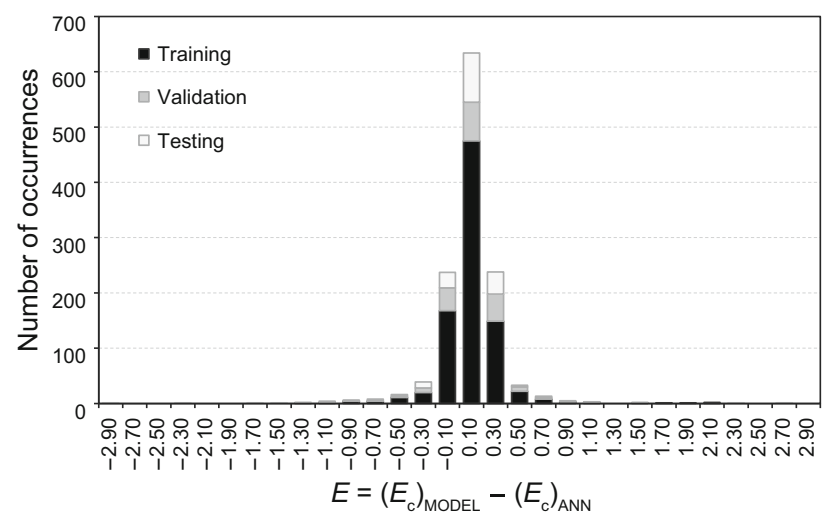

Fig. 16 Histogram of calculated errors of training, validation, and testing sets

(6) An ANN-based proxy model is successfully trained, and the resulting model can be used as a quick screening tool to estimate the discounted process efficiency, once corresponding operational and reservoir/hydraulic-fracture parameters are provided. The model was able to estimate the efficiency of 188 cases that it had not seen before with a correlation coefficient of 0.96 .

Open Access This article is distributed under the terms of the Creative Commons Attribution 4.0 International License (http://crea tivecommons.org/licenses/by/4.0/), which permits unrestricted use, distribution, and reproduction in any medium, provided you give appropriate credit to the original author(s) and the source, provide a link to the Creative Commons license, and indicate if changes were made.

\section{References}

Abboud A. A study of cyclic injection of nitrogen on Mid-Continent crude oil: an investigation of the vaporization process in low pressured shallow reservoirs. M.Sc. thesis, The Pennsylvania State University, University Park, Pennsylvania; 2005. 
Alizadeh B, Najjari S, Ali K. Artificial neural network modelling and cluster analysis for organic facies and burial history estimation using well log data: a case study of the South Pars Gas Field, Persian Gulf, Iran. Comput Geosci. 2012;45:261-9. doi:10.1016/ j.cageo.2011.11.024.

Amirian E, Leung J, Zanon S, et al. Data-driven modeling approach for recovery performance prediction in SAGD operations. In: SPE heavy oil conference, Calgary, 11-13 June; 2013. doi:10. 2118/165557-MS.

Artun E, Ertekin T, Watson R, et al. Development and testing of proxy models for screening cyclic pressure pulsing process in a depleted, naturally fractured reservoir. J Pet Sci Eng. 2010;73(1):73-5. doi:10.1016/j.petrol.2010.05.009.

Artun E, Ertekin T, Watson R, et al. Performance and economic evaluation of cyclic pressure pulsing in naturally fractured reservoirs. J Can Pet Technol. 2011a;50(9-10):24-36. doi:10. 2118/129599-PA.

Artun E, Ertekin T, Watson R, et al. Development of universal proxy models for screening and optimization of cyclic pressure pulsing in naturally fractured reservoirs. $J$ Nat Gas Sci Eng. 2011b;3(6):667-86. doi:10.1016/j.jngse.2011.07.016.

Artun E, Mohaghegh S. Intelligent seismic inversion workflow for high-resolution reservoir characterization. Comput Geosci. 2011;37(2):143-57. doi:10.1016/j.cageo.2010.05.007.

Artun E, Ertekin T, Watson R, et al. Designing cyclic pressure pulsing in naturally fractured reservoirs using an inverse looking recurrent neural network. Comput Geosci. 2012;2012(38):68-79. doi:10. 1016/j.cageo.2011.05.006.

Artun E. Characterizing interwell connectivity in waterflooded reservoirs using data-driven and reduced-physics models: a comparative study. Neural Comput Appl. 2016. doi:10.1007/ s00521-015-2152-0.

Ayala L, Ertekin, T. Analysis of gas-cycling performance in gas/condensate reservoirs using neuro-simulation. In: SPE annual technical conference and exhibition, Dallas, 9-12 October; 2005. doi:10.2118/95655-MS.

Bardon C, Karaoguz D, Tholance M. Well stimulation by $\mathrm{CO}_{2}$ in the heavy oil field of Camurlu in Turkey. In: SPE enhanced oil recovery symposium, Tulsa, 20-23 April; 1986. doi:10.2118/ 14943-MS.

Bardon C, Corlay P, Longeron D, et al. $\mathrm{CO}_{2}$ huff ' $\mathrm{n}$ ' puff revives shallow light-oil-depleted reservoirs. SPE Reserv Eng. 1994;9(2):92-100. doi:10.2118/22650-PA.

Boswell R, Pool S, Pratt S, et al. Appalachian Basin low-permeability sandstone reservoir characterizations. Final Contractor's Report to the U.S. Department of Energy. Contract No. DE-AC2190MC26328, Report No. 94CC-R91-003; 1993. doi:10.2172/ 1030788.

Centilmen A, Ertekin T, Grader A. Applications of neural networks in multiwell field development. In: SPE annual technical conference and exhibition, Houston, 3-6 October; 1999. doi:10.2118/ 56433-MS

CMG: Computer Modeling Group Advanced Compositional Reservoir Simulator (GEM) User's Guide. Version 2013. Calgary, Alberta, Canada; 2013.

Cullick A, Johnson D, Shi G. Improved and more rapid history matching with a nonlinear proxy and global optimization. In: SPE annual technical conference and exhibition, San Antonio, 24-27 September; 2006. doi:10.2118/101933-MS.

Doraisamy H, Ertekin T, Grader A. Field development studies by neuro-simulation: an effective coupling of soft and hard computing protocols. Comput Geosci. 2000;26(8):963-73. doi:10.1016/S0098-3004(00)00032-7.

Duda J, Overbey W, Johnson H. Predicted oil recovery by waterflood and gas drive, Bradford Third and Sartwell Sands, Sartwell
Oilfield, McKean County, PA. U.S. Department of The Interior, Bureau of Mines, Report of Investigations No. 6943; 1967.

Esmaili S, Mohaghegh S. Full field reservoir modeling of shale assets using advanced data-driven analytics. Geosci Front. 2015;7(1):11-20. doi:10.1016/j.gsf.2014.12.006.

Farias M, Watson R. Interaction of nitrogen/ $\mathrm{CO}_{2}$ mixtures with crude oil. Report to the U.S. Department of Energy. Contract No. DEFC26-04NT42098; 2007.

Fausett L. Fundamentals of neural networks: architectures, algorithms, and applications. Englewood Cliffs: Prentice-Hall; 1994.

Felsenthal M, Ferrell H. Pressure pulsing: an improved method of waterflooding fractured reservoirs. In: SPE Permian Basin oil recovery conference, Midland, Texas, 8-9 May; 1967. doi:10. 2118/1788-MS.

Gamadi T, Sheng J, Soliman M, et al. An experimental study of cyclic $\mathrm{CO}_{2}$ injection to improve shale oil recovery. In: SPE improved oil recovery symposium, 12-16 April, Tulsa, Oklahoma; 2014. doi:10.2118/169142-MS.

Guyaguler B. Optimization of well placement and assessment of uncertainty. Ph.D. dissertation, Stanford University, Stanford, California; 2002.

Haskin $\mathrm{H}$, Alston R. An evaluation of $\mathrm{CO}_{2}$ huff ' $\mathrm{n}$ ' puff tests in Texas. SPE Reserv Eng. 1989;41(2):177-84. doi:10.2118/15502PA.

Johnson V, Rogers L. Applying soft computing methods to improve the computational tractability of a subsurface simulation-optimization problem. J Pet Sci Eng. 2011;29(3-4):153-75. doi:10. 1016/S0920-4105(01)00087-0.

Kalantari-Dhaghi A, Mohaghegh S, Esmaili S. Data-driven proxy at hydraulic fracture cluster level: a technique for efficient $\mathrm{CO}_{2^{-}}$ enhanced gas recovery and storage assessment in shale reservoir. J Nat Gas Sci Eng. 2015;27(2):515-30. doi:10.1016/j.jngse. 2015.06.039.

Khatib A, Earlougher R, Kantar K. $\mathrm{CO}_{2}$ injection as an immiscible application for enhanced recovery in heavy oil reservoirs. In: SPE California regional meeting, Bakersfield, 25-27 March; 1981. doi:10.2118/9928-MS

Kelton W, Barton R. Experimental design for simulation. In: Winter simulation conference, New Orleans, 7-10 December; 2003.

Marrero T, Mason E. Gaseous diffusion coefficients. J Phys Chem Ref Data. 1972;1(1):3-118. doi:10.1063/1.3253094.

MATLAB: Neural network toolbox; Version 2013a, Mathworks, Inc., Natick, Massachusetts; 2013.

Miller B, Gaudin R. Nitrogen huff and puff process breathes new life into old field. World Oil Mag. 2000;221(9):7-8.

Mohaghegh S, Balan B, McVey D, et al. A hybrid neuro-genetic approach to hydraulic fracture treatment design and optimization. In: SPE annual technical conference and exhibition, Denver, 6-9 October; 1996. doi:10.2118/36602-MS.

Mohaghegh S, Al-Mehairi Y, Gaskari R, et al. Data-driven reservoir management of a giant mature oilfield in the Middle East. In: SPE annual technical conference and exhibition, 27-29 October, Amsterdam; 2014. doi:10.2118/170660-MS.

Monger TG, Coma JM. A laboratory and field evaluation of the $\mathrm{CO}_{2}$ huff ' $n$ ' puff process for light-oil recovery. SPE Reserv Eng. 1988;3(4):1168-76. doi:10.2118/15501-PA.

Neuroshell: Neuroshell 2 tutorial. Ward Systems, Inc., Frederick, Maryland; 1998.

Owens W, Archer D. Waterflood pressure pulsing for fractured reservoirs. J Pet Technol. 1966;18(6):745-52. doi:10.2118/1123PA.

Parada C, Ertekin T. A new screening tool for improved oil recovery methods using artificial neural networks. In: SPE western regional meeting, Bakersfield, 19-23 March; 2012. doi:10. 2118/153321-MS. 
Patel A, Davis D, Guthrie C, et al. Optimizing cyclic steam oil production with genetic algorithms. In: SPE western regional meeting, Irvine, 30 March-1 April; 2005. doi:10.2118/93906MS.

Prats M. Thermal recovery. New York: SPE of AIME; 1982.

Raeesi M, Moradzadeh A, Ardejani F, et al. Classification and identification of hydrocarbon reservoir lithofacies and their heterogeneity using seismic attributes, $\operatorname{logs}$ data and artificial neural networks. J Pet Sci Eng. 2012;82-83:151-65. doi:10. 1016/j.petrol.2012.01.012.

Raza SH. Water and gas cyclic pulsing method for improved oil recovery. J Pet Technol. 1971;23(12):1467-74. doi:10.2118/ 3005-PA.

Sankur V, Emanuel A. A laboratory study of heavy oil recovery with $\mathrm{CO}_{2}$ injection. In: SPE California regional meeting, Ventura, 23-25 March; 1983. doi:10.2118/11692-MS.

Shayegi S, Jin Z, Schenewerk P, et al. Improved cyclic stimulation using gas mixtures. In: SPE annual technical conference and exhibition, Denver, 6-9 October; 1996. doi:10.2118/36687-MS.

Shelton J, Morris E. Cyclic injection of rich gas into producing wells to increase rates from viscous-oil reservoirs. J Pet Technol. 1973;25(8):890-6. doi:10.2118/4375-PA.

Sheng J, Chen K. Evaluation of the EOR potential of gas and water injection in shale oil reservoirs. J Unconv Oil Gas Resour. 2014;5:1-9. doi:10.1016/j.juogr.2013.12.001.

Sheng J. Enhanced oil recovery in shale reservoirs by gas injection. J Nat Gas Sci Eng. 2015;22:252-9. doi:10.1016/j.jngse.2014.12. 002.
Sigmund PM. Prediction of molecular diffusion at reservoir conditions. Part $1-$ measurement and prediction of binary dense gas diffusion coefficients. J Can Pet Technol. 1976;15(2):48-57. doi:10.2118/76-02-05.

Silva FV, Belery P. Molecular diffusion in naturally fractured reservoirs: a decisive recovery mechanism. In: SPE annual technical conference and exhibition, San Antonio, 8-11 October; 1989. doi:10.2118/SPE-19672-MS.

Silva P, Clio M, Schiozer D. Use of neuro-simulation techniques as proxies to reservoir simulator: application in production history matching. J Pet Sci Eng. 2007;57(3-4):273-80. doi:10.1016/j. petrol.2006.10.012.

Yeten B, Durlofsky L, Aziz K. Optimization of nonconventional well type, location, and trajectory. SPE J. 2003;8(3):200-10. doi:10. 2118/86880-PA.

Zangl G, Giovannoli M, Stundner M. Application of artificial intelligence in gas storage management. In: SPE Europec/EAGE annual conference and exhibition, 12-15 June; 2006. doi:10. 2118/100133-MS.

Zhao H, Kang Z, Zhang X, et al. INSIM: a data-driven model for history matching and prediction for waterflooding monitoring and management with a field application. In: SPE reservoir simulation symposium, 23-25 February, Houston; 2015. doi:10. 2118/173213-MS 